\title{
Effects of Crystalline Anisotropy on Fluid Distribution in Ultramafic Partial Melts
}

\author{
HARVE S. WAFF AND ULRICH H. FAUL
}

Department of Geological Sciences, University of Oregon, Eugene

\begin{abstract}
The textures of experimentally produced ultramafic partial melts show consistent and significant deviations from the morphology predicted by isotropic equilibrium theory. Flat crystalline interfaces are pervasive in these systems and they coexist with smoothly curved boundaries which are predicted by the isotropic theory. Long-duration experimental runs on olivine-basalt mixtures held at pressures between 1.0 and $2.0 \mathrm{GPa}$ and temperatures from $1350^{\circ} \mathrm{C}$ to $1400^{\circ} \mathrm{C}$ were evaluated. Scanning electron microscope images of samples with 2.5 or more volume percent melt showed at least $20 \%$ of observable grain boundaries to be wetted by the melt. In addition, approximately $60 \%$ of the melt tubules occurring along triple junctions in this sample were found to have at least one flat interface, an effect which increases the ratio of permeability to porosity. Both the experimental evidence and theoretical considerations indicate that the flat faces are stable equilibrium or steady state features in these partial melts, and that they are crystallographically controlled. The crystal-melt morphology is influenced by the crystalline equilibrium habit (obtained from minimization of surface energies of individual crystals) under the constraints of polycrystalline aggregates. A dependence of the style of melt distribution on melt fraction was observed in these runs. At very low melt fractions (less than 1 vol \%) the texture is dominated by melt-filled triple junctions and mostly dry grain boundaries, whereas at higher melt fractions (but below 5 vol \%) more melt pockets and melt films along grain boundaries appear. An interpretation of the observed texture is made, applying established crystal growth and interface theories to steady state partially molten systems. The extensive occurrence of flat or faceted crystallographic faces in partial melts requires major changes in the modeling of their permeabilities, as well as bulk elastic, anelastic, and electrical properties, from existing models of melt distribution. In regions of the upper mantle where olivine lattice preferred orientation is expected (e.g., in the vicinity of mid-ocean ridges) the presence of faceted faces and associated changes in melt distribution will produce anisotropic permeabilities and changes in seismic attenuation.
\end{abstract}

\section{INTRODUCTION}

Our knowledge of the evolutionary processes of the Earth's past and present state and dynamics are dependent on an understanding of the nature of partial melting. An important part of this process is liquid distribution in rocks as they are heated above their solidus temperatures. Initial melt distributions are transient configurations. Surface tensions on various interfaces between crystalline grains and between liquid and crystalline grains constitute driving forces which tend to bring the interfacial geometry toward a steady state configuration. If surface energies and surface tensions were isotropic in a system, then mechanical and chemical equilibria would require a constant wetting angle (contact angle between the melt and two adjoining crystalline grains) and constant mean liquid-solid interface curvature [Bulau et al., 1979].

The description of partial melt morphology provided by isotropic equilibrium modeling has become fairly widely accepted for the Earth's upper mantle [Waff and Bulau, 1979; Cooper and Kohlstedt, 1982; Watson, 1982; Fujii et al., 1986; Toramaru and Fujii, 1986; von Bargen and Waff, 1986; Watson et al., 1990]. The smoothly curved interfaces observed experimentally in our laboratory required 7 to 15 days to develop in high-pressure/high-temperature experiments with basalt-olivine mixtures [Waff and Bulau, 1982]. The

Copyright 1992 by the American Geophysical Union

Paper number 92JB00066

0148-0227/92/92JB-00066\$05.00 appearance of these interfaces was interpreted as evidence that the partial melts were closely approaching textural equilibrium after the indicated run durations.

However, significant deviations from the partial melt texture predicted by the isotropic equilibrium model can be found throughout the pertinent literature as well as in samples produced in our laboratory. Flat faces, as well as sharp corners, are pervasive on olivine crystals in contact with the melt for a variety of bulk compositions. Examples are natural lherzolite (the sample was beld at $1375^{\circ} \mathrm{C}$ and $1.5 \mathrm{GPa}$ for 2.5 months [Maaløe, 1981]; see also Nicolas and Prinzhofer [1983]), a synthetic peridotite [Fujii et al., 1986], a Co-Mg olivine-basalt aggregate [Green et al., 1990], a synthetic glass-San Carlos olivine mixture [Riley and Kohlstedt, 1991], and the olivinebasalt mixtures used in our laboratory. Little attention has been given to the flat interfaces. We regarded them, apparently along with other researchers, to be unimportant as determinants of partial melting geometries for the mantle. They were interpreted as the result of transient, localized recrystallization associated mainly with dissolution of small olivine grains. Because time scales in the earth are considerably longer than in laboratory experiments, these features were, using this interpretation, expected to disappear in mantle partial melts.

In this paper we present evidence for the existence of the flat crystal-melt interfaces in long-duration high-pressure/hightemperature experiments, review theoretical models confirming the effects of crystalline anisotropy on interface morphology as stable equilibrium or steady state features of partial melts, and discuss some consequences, especially where inferred grain alignment emphasizes crystallographically controlled permeability. 
EXPERIMENTAL EVIDENCE FOR COEXISTING Flat AND CuRved INTERFaces in OLIVINE-BASALT Partial MelTS

\section{Experimental Procedures}

Three recent experiments were conducted in a conventional piston-cylinder apparatus to assess the effects of olivine anisotropy on the crystal-melt morphology, as olivine is known to have the strongest anisotropic properties among the important upper mantle minerals. The starting materials and experimental conditions are given in Table 1 , and the starting compositions and postrun olivine composition of run 3 are shown in Table 2. The sample material was not dried prior to encapsulation in the sample chambers, and starting olivine grain size was between 45 and $62 \mu \mathrm{m}$. The basalt was very finely powdered and mixed with the olivine. A cross section of the sample chamber assembly used in runs 2 and 3 is shown in Figure 1. This assembly provides stable pressure and temperature conditions for durations of at least 1 month based on calibrations performed using the quartz-coesite and liquid-solid gold phase transitions, and on the observation of constant furnace power input for maintenance of a given temperature after initial stabilization. Tungsten-5\% rhenium versus tungsten-26\% rhenium thermocouples were used for temperature measurement because of their known long term stability at high temperatures. During quench, temperature dropped by more than $300^{\circ} \mathrm{C}$ during the first second. For conditions of earlier runs which are also discussed in this paper, see Waff and Bulau [1979, 1982] and von Bargen and Waff [1988]. An almost purely hydrostatic stress environment was achieved in these runs. This was indicated by the extremely low measured edge dislocation density of an olivine crystal from a previous experiment at similar $\mathrm{P}, \mathrm{T}$ conditions and duration run in this laboratory (R.F. Cooper, private communication, 1984).

\section{Sample Evaluation}

Run products were evaluated as follows: (1) electron microprobe analysis was used to determine phase compositions and homogeneity, (2) back scattered electron (BSE) images were obtained with a scanning electron microscope to portray texture, and (3) universal stage optical microscopy was used to determine crystal axes of selected grains. For these purposes, 20 - to $30-\mu \mathrm{m}$-thin sections from vertical slices through the center of the sample were mounted on glass slides and polished
TABLE 2. Composition of Sample Material

\begin{tabular}{lrrrrr}
\hline & Olivine $^{\mathrm{a}}$ & $\begin{array}{r}\text { AOB- } \\
\mathrm{C70}\end{array}$ & Olivine $^{\mathrm{b}}$ & Olivine $^{\mathrm{c}}$ & $7^{76 \mathrm{~K}^{\mathrm{d}}}$ \\
\hline $\mathrm{SiO}_{2}$ & 40.49 & 47.54 & 40.86 & 40.34 & 45.33 \\
$\mathrm{Al}_{2} \mathrm{O}_{3}$ & & 16.14 & & & 11.73 \\
$\mathrm{FeO}^{\mathrm{e}}$ & 10.48 & 14.29 & 9.53 & 9.92 & 12.10 \\
$\mathrm{MgO}$ & 48.10 & 5.09 & 50.07 & 48.45 & 12.96 \\
$\mathrm{CaO}$ & & 9.13 & 0.06 & 0.20 & 10.36 \\
$\mathrm{Na}_{2} \mathrm{O}$ & & 3.42 & & & 2.31 \\
$\mathrm{~K}_{2} \mathrm{O}$ & & 1.21 & & & 0.78 \\
$\mathrm{TiO}_{2}$ & & 47.54 & & & 2.32 \\
$\mathrm{P}_{2} \mathrm{O}_{5}$ & & 0.58 & & & 0.33 \\
$\mathrm{MnO}$ & & 0.18 & 0.00 & 0.13 & 0.17 \\
$\mathrm{Cr}_{2} \mathrm{O}_{3}$ & & & 0.00 & 0.02 & 0.05 \\
$\mathrm{NiO}$ & & & 0.44 & 0.17 & 0.10 \\
$\mathrm{Total}$ & 99.07 & 100.81 & 101.10 & 99.24 & 98.54 \\
\hline
\end{tabular}

Compositions are given in weight percent.

a Hualalai olivine.

b San Carlos olivine, average of 10 points before the experiments.

' Postrun olivine, average of 10 points.

Average of 7 points.

${ }^{e} \mathrm{FeO}$ is total Fe reported as $\mathrm{FeO}$.

but not etched. Etching tends to selectively remove glass which can compromise textural observations.

Microprobe analysis of postrun olivine grains indicates that they were of uniform composition throughout the samples. With a $2 \mu \mathrm{m}$ beam diameter no zonation could be detected when stepping from the core to the rim of a grain approximately 65 $\mu \mathrm{m}$ in diameter. Reaction of the prerun San Carlos olivine with the basalt is indicated by slight $\mathrm{Fe}$ and $\mathrm{Ca}$ enrichment and loss of $\mathrm{Ni}$ during the experiment (Table 2). The melt fractions of runs 2 and 3 were 3.5 vol $\%$ and 2.5 vol $\% \pm 0.5 \%$, determined by point count on the microprobe. The melt fraction of run 1 was estimated at less then 1 vol \% from BSE images. Very small uniform quench borders (less than one $\mu \mathrm{m}$ thick) are observed on olivine grains in run 3, similar to those described by Green [1976]. However, they do not alter the texture significantly because of their relatively small thickness compared with the average grain size.

TABLE 1. Experimental Conditions and Starting Material of Partial Melt Runs

\begin{tabular}{|c|c|c|c|c|c|c|}
\hline Run & $\begin{array}{c}\text { Pressure, } \\
\text { GPa }\end{array}$ & $\begin{array}{c}\text { Temperature, } \\
{ }^{\circ} \mathrm{C}\end{array}$ & $\begin{array}{c}\text { Duration, } \\
\text { hours }\end{array}$ & $\begin{array}{l}\text { Starting Material } \\
\text { (by weight) }\end{array}$ & $\begin{array}{l}\text { Sample } \\
\text { Chamber }\end{array}$ & $\begin{array}{l}\text { Approximate } \\
\text { Melt Fraction }\end{array}$ \\
\hline 1 & 1.0 & 1350 & 530 & $\begin{array}{c}\text { 98.5\% olivine } \text { a }^{\mathrm{a}}+ \\
1.5 \% \text { AOB-C70 } \\
\text { basalt }^{\mathrm{b}}\end{array}$ & $\begin{array}{l}\text { high-purity } \\
\text { iron }\end{array}$ & $<1.0 \%$ \\
\hline 2 & 1.5 & 1400 & 320 & $\begin{array}{l}95 \% \text { olivine }+ \\
5 \% 76 \mathrm{~K} 6 \text { basalt }^{\mathrm{d}}\end{array}$ & graphite & $3.5 \%$ \\
\hline 3 & 2.0 & 1400 & 360 & $\begin{array}{c}95 \% \text { olivine }{ }^{c}+ \\
5 \% 76 \mathrm{~K} 6 \text { basalt }^{d}\end{array}$ & graphite & $2.5 \%$ \\
\hline
\end{tabular}

a Olivine from the interior of a dunite xenolith, Hualalai volcano, Hawaii [Jackson, 1968].

b Hawaiian olivine basalt (classification of MacDonald and Katsura [1964]).

c Olivine from San Carlos, New Mexico.

A Alkaline basalt [Clague and Dalrymple, 1988]. 


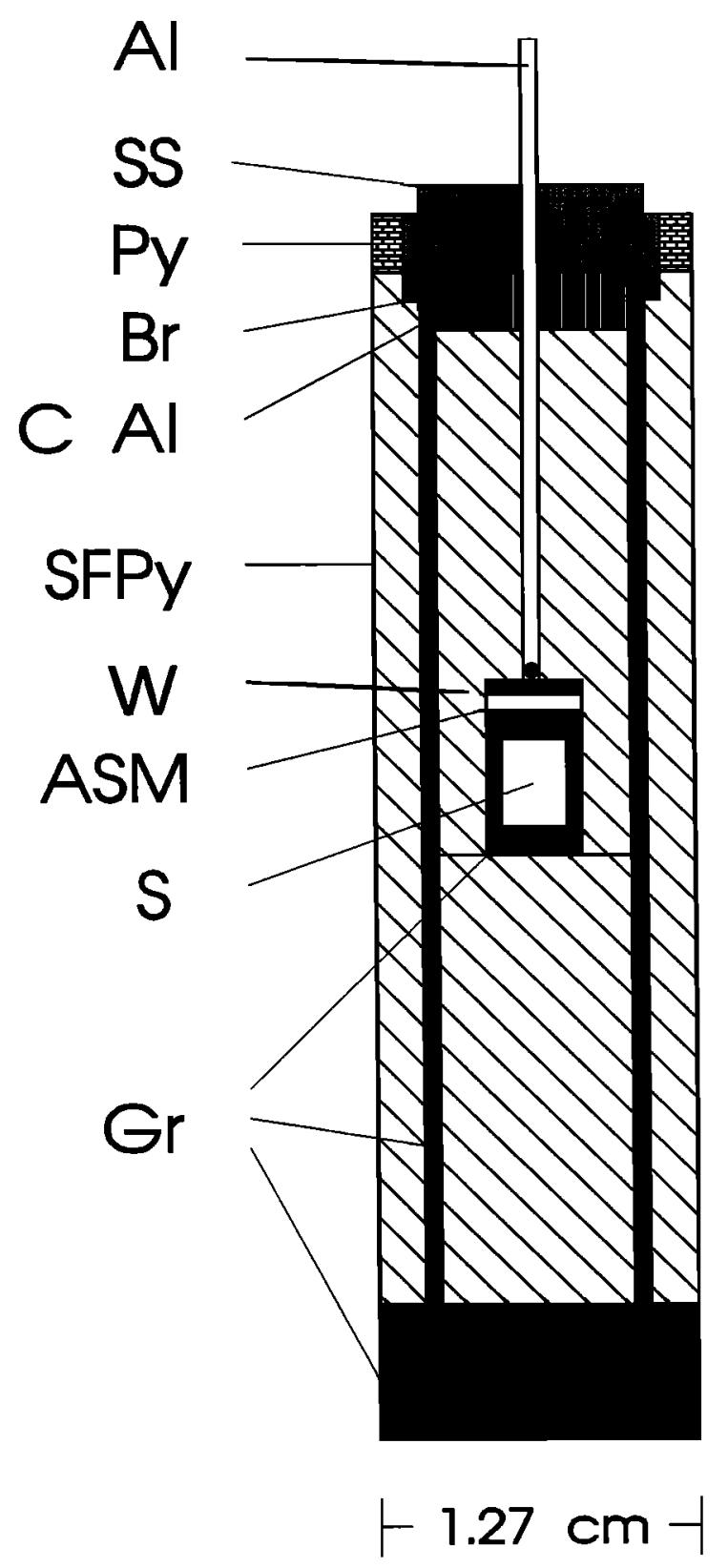

Fig. 1. Sample chamber assembly used in the piston-cylinder apparatus for long duration runs 2 and 3. Anhydrous materials were used throughout to reduce possible thermocouple contamination via reaction. $\mathrm{Al}$ is a bored aluminum tube; $\mathrm{SS}$, stainless steel; $\mathrm{Py}$, unfired pyrophyllite; $\mathrm{Br}$, brass ring; C Al, crushable aluminum; SFPy, soft fired pyrophyllite; W, tungsten foil disk; ASM, AlSiMg disk; S, sample material; and Gr, graphite.

The presence of a few pyroxene grains in postrun samples indicates that the melt was in equilibrium with pyroxene and olivine. Melt compositions are, therefore, considered to be reasonable analogues of primary mid-ocean ridge basalts (MORBs) [Elthon, 1989]. Attainment of near-equilibrium or steady state conditions is extremely important for experimental studies of the type reported here. Unless complete chemical equilibrium of crystalline grains with the melt is reached, strong driving forces for diffusion will still be present and can result in transient surface morphologies. Diffusion coefficients of the order of $10^{-11} \mathrm{~cm}^{2} / \mathrm{s}$ for various cations of olivine at $2.0 \mathrm{GPa}$ and $1430^{\circ} \mathrm{C}$ [Jurewicz and Watson, 1988] allow complete chemical equilibration of individual crystalline grains over the time scales of our runs. The uniform composition of the olivine grains and the hydrostatic stress environment achieved during experiments indicate good equilibration of the sample material where driving forces for diffusion and recrystallization are largely absent, except for steady state Ostwald ripening [cf. Jurewicz and Watson, 1985].

Grain boundaries are not visible in the BSE images of polished but not etched samples unless they contain some material such as glass, whose mean atomic number differs from that of the olivine grains (cf. Figure 2). The presence of glass on some grain boundary surfaces away from edge intersections may have been obscured in the past by mild etching of the surface and by poorer instrumental resolution. Optical photomicrographs tend to obscure the grain boundary-melt geometry by averaging images over a finite focal depth range. It is, therefore, often difficult to match them with BSE images of the same part of the sample.

\section{Experimental Observations}

We observe the following types of melt geometries: (1) meltfilled triple junctions with smooth curvature at all three grain intersections, mostly less than $4 \mu \mathrm{m}$ wide (Figures 3 and 4 ) or one flat face in contact with two smoothly curved interfaces (Figure 5), (2) melt "pockets" bounded by more than three grains, often associated with flat interfaces, which are typically much larger than the triple junctions (Figures 2 and 6), and (3) melt "films" (of the order of microns) between two adjacent grains with flat interfaces (Figure 7) or one flat and one curved interface (Figure 8). The term flat, used in the above context, refers to flatness on the scale of the photomicrographs and does not imply that a very small curvature could not exist.

The network of interconnected, melt-filled tubules along most three-grain-edge intersections occurs pervasively in all longduration experiments performed in this laboratory to date. A substantial number of the tubules involve at least one flat meltcrystal interface coexisting with curved interfaces. BSE images of run 3, with $2.5 \mathrm{vol} \%$ melt, showed approximately $60 \%$ of 57 well-characterized triple junctions to have at least one flat face coexisting with smoothly curved interfaces. We note that most of the volume of the melt in this run resides in pockets and films, not in the triple junctions. The melt-filled tubules are not observed to grow beyond a certain effective diameter with increasing melt fraction as would be expected from isotropic equilibrium theory [cf. Figure 5 in von Bargen and Waff, 1986]. No triple junction with three curved interfaces (such as in Figure 3) was found to be more than $8 \mu \mathrm{m}$ in effective diameter in any experiment, even with melt fractions as high as 9 vol \% in an earlier experiment.

The melt pockets observed are not isolated, but are interconnected by the network of triple-junction tubules and by the melt films existing along some grain boundaries. The number of melt films present and the deep penetration of melt between grains away from some triple junctions, where one flat face coexists with two curved faces, suggest complete wetting of a significant fraction of the grain boundaries. At the small melt fractions of the experimental charges of this study, only a very small percentage of triple junctions would be expected to lie in the plane of the surfaces imaged with the SEM. These melt features would have the appearance of wetted films in two dimensional views. However, such films would not exhibit flat, parallel boundaries with adjacent crystal grains. Most of the grain boundaries observed to be wetted by the melt in the 


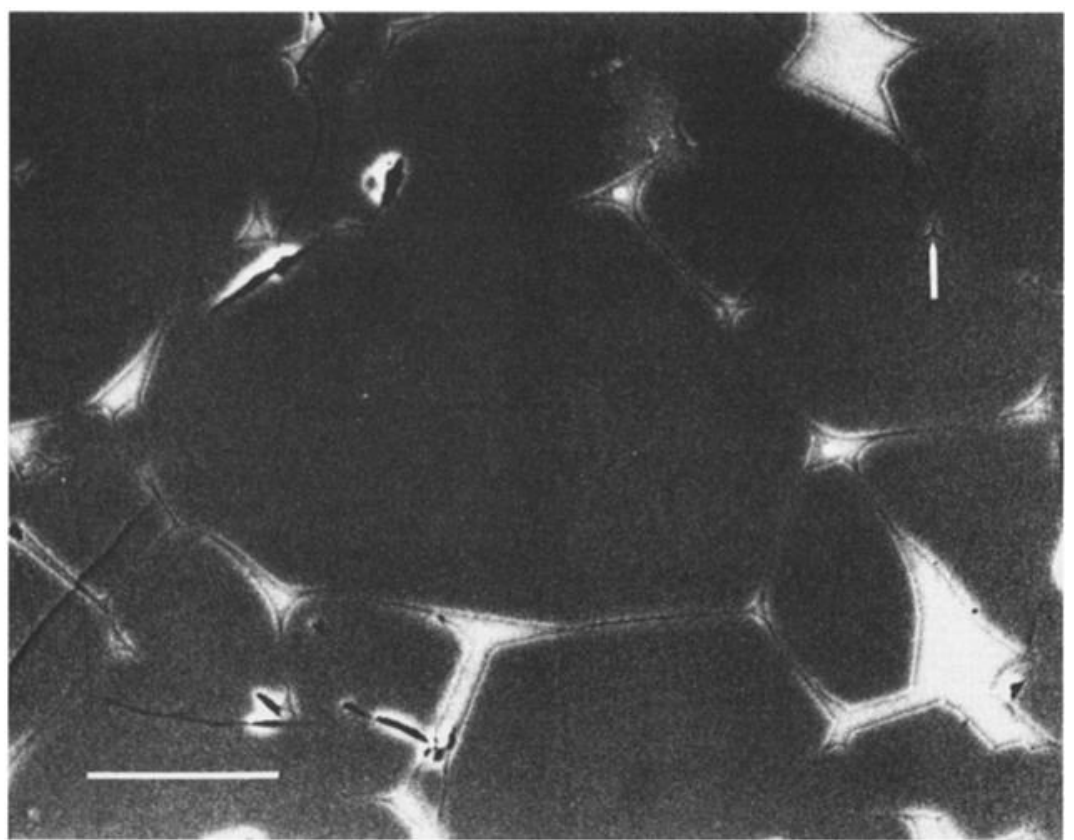

Fig. 2. Representative melt distribution in BSE image of partial melt run 3. The overall melt fraction is about $2.5 \%$. Lighter grey areas are glass, darker areas are olivine grains. Grain boundaries are only visible with adjacent glass. All characteristic textural features are present in this photograph. The arrow indicates the triple junction in Figure 3. Solid areas and lines are cracks not present during the experiment. Scale bar represents $30 \mu \mathrm{m}$.

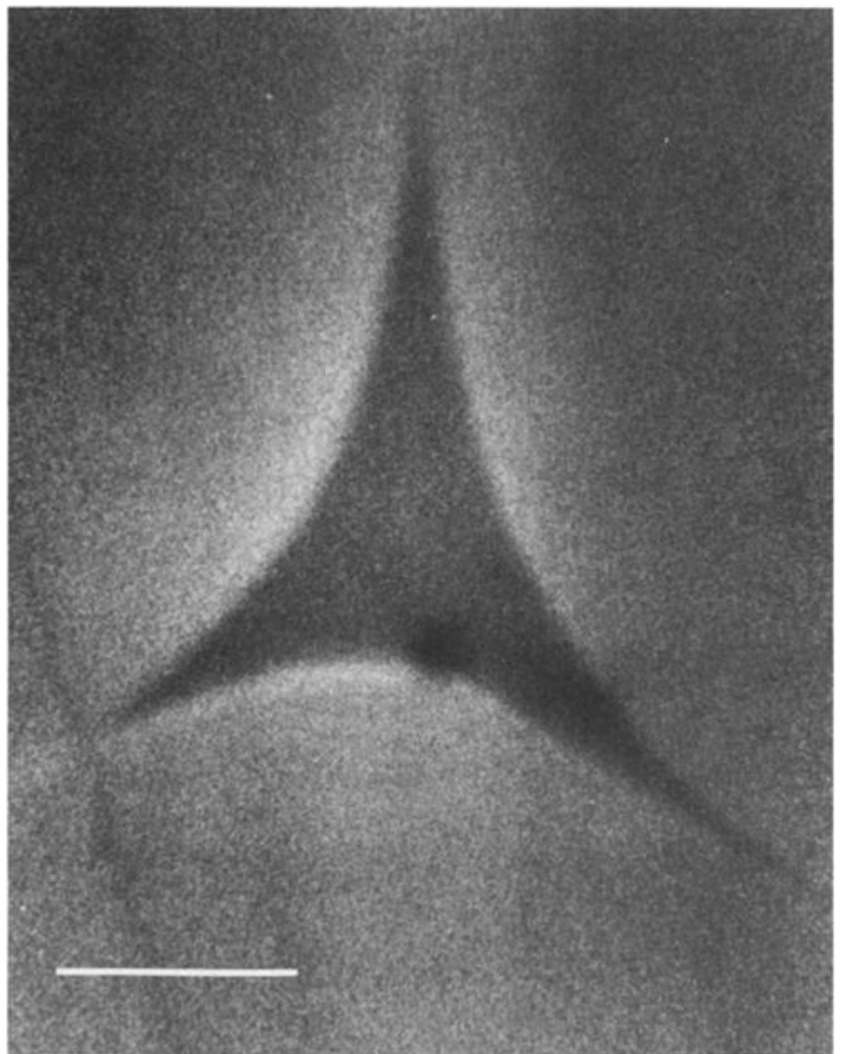

Fig. 3. A three-grain-edge intersection magnified from the top right corner of Figure 2. This type of triple junction, in which crystal melt interfaces approximate constant mean curvature, can be found throughout all samples, although they are relatively small in cross-sectional area compared with other melt regions. Scale bar represents $1 \mu \mathrm{m}$. sectional views imaged in this study have uniform thicknesses over most, if not all, of their of their observed lengths, indicating that they are not due to axial cuts along triple junctions. Furthermore, the observed percentage of melt films at grain boundaries is much too large to be due to melt-filled triple junctions along three grain intersections cut along their axes.

The number of wetted grain boundaries at very low melt fractions (below $1 \mathrm{vol} \%$ ) is small, presumably because most of the melt can be accommodated along the triple junctions. Some of the long-duration experiments reported earlier [Waff and Bulau, 1979; Vaughan et al., 1982] had melt fractions less than 1 vol $\%$ and textures dominated by triple junctions and dry grain boundaries. Vaughan et al. [1982], in a transmission electron microscopy (TEM) study, reported that virtually all grain boundaries were free of glass. However, a few boundaries with glass layers 10 to $50 \mathrm{~nm}$ thickness and some crystallographically controlled solid-liquid interfaces which were parallel to the $(010)$ plane were observed. It should be noted that only a small fraction of the grain boundaries present in the samples of this TEM study could actually be observed in the feathered edges of the sample foils prepared by ion thinning. The results of Vaughan et al. [1982] contrast with observations of complete grain boundary wetting in a number of ceramic systems involving silicates, with film thicknesses of the order of $2 \mathrm{~nm}$ (cf. Clarke, 1987). A basic difference in the experimental run conditions of the olivine basalt and the ceramic partial melts accounts for the differences in film thicknesses observed in the two contrasting cases. The ceramic systems were open to fluid flow out of the crystalline matrix, whereas the olivine basalt system was equilibrated as a closed system. In the latter case, and in the study reported in this paper, the respective melt fractions were constrained by the values of $P, T$, and composition. 


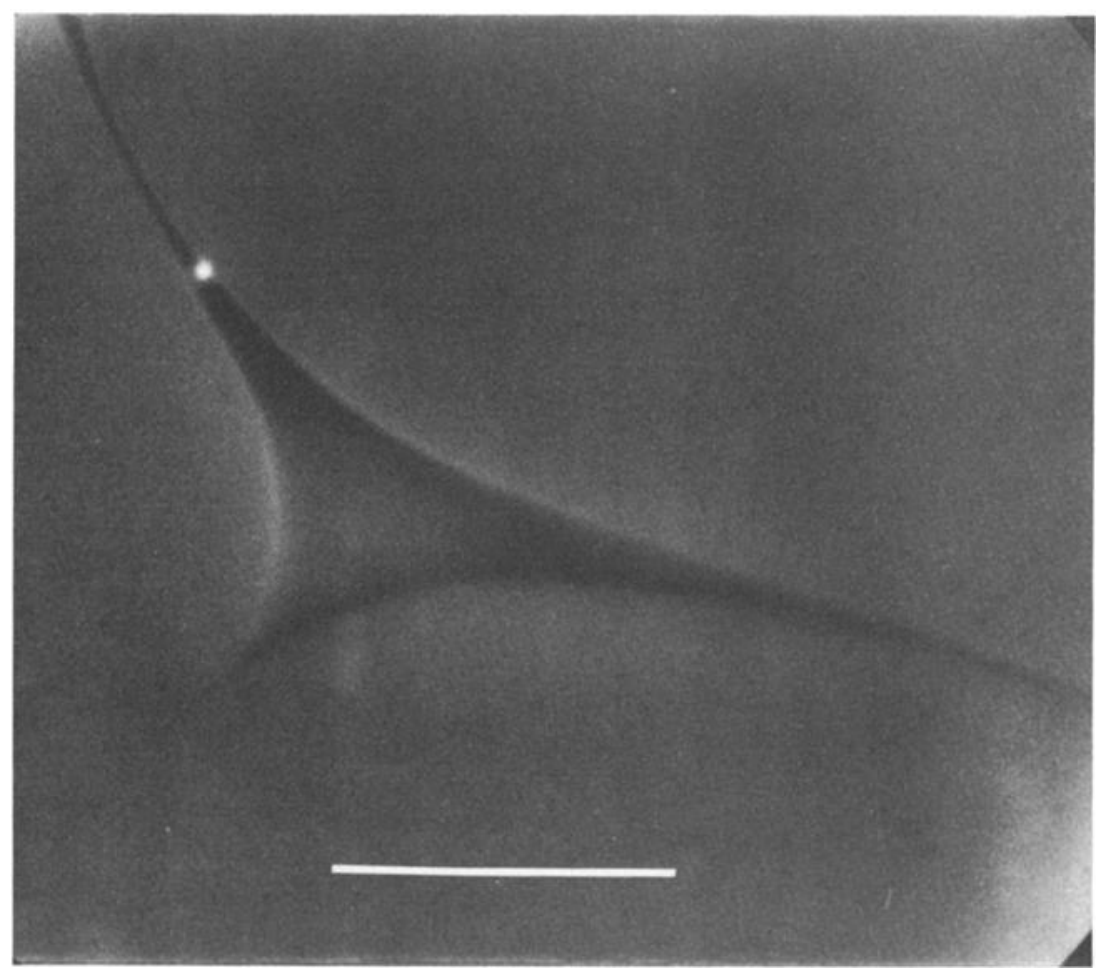

Fig. 4. BSE image from run 1: triple junction with constant interfacial curvature. The melt extends deeply between the grain boundaries compared with the junctions of Figure 3. Scale bar represents $10 \mu \mathrm{m}$.

The determination of crystallographic axes of individual grains in the run products reported in the present study was a difficult and lengthy process. The major reason was that the grain size was limited to allow complete chemical equilibration of the grain interior by solid state diffusion. As a result, many grains were not much larger than the thickness of the thin sections. Thermal contraction during quenching resulted in horizontally fractured samples, and additional fracturing occurred during cutting and polishing of the thin sections. Therefore, only a relatively small fraction of grains could be oriented and the Miller indices of some of their faces in contact with the melt determined. We were able to resolve 12 sets of

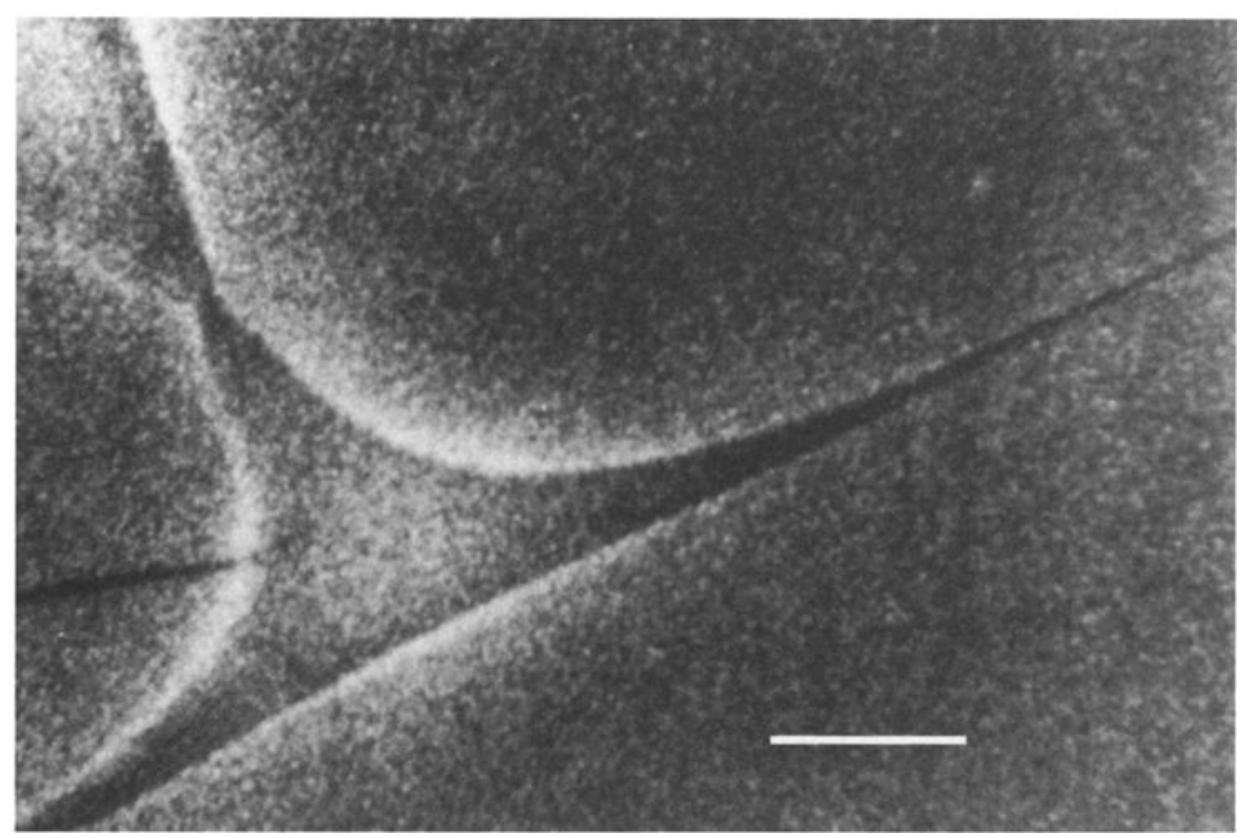

Fig. 5. BSE image from run 2. Two smoothly curved grain edges in contact with a flat grain boundary. Scale bar represents 2 $\mu \mathrm{m}$. 

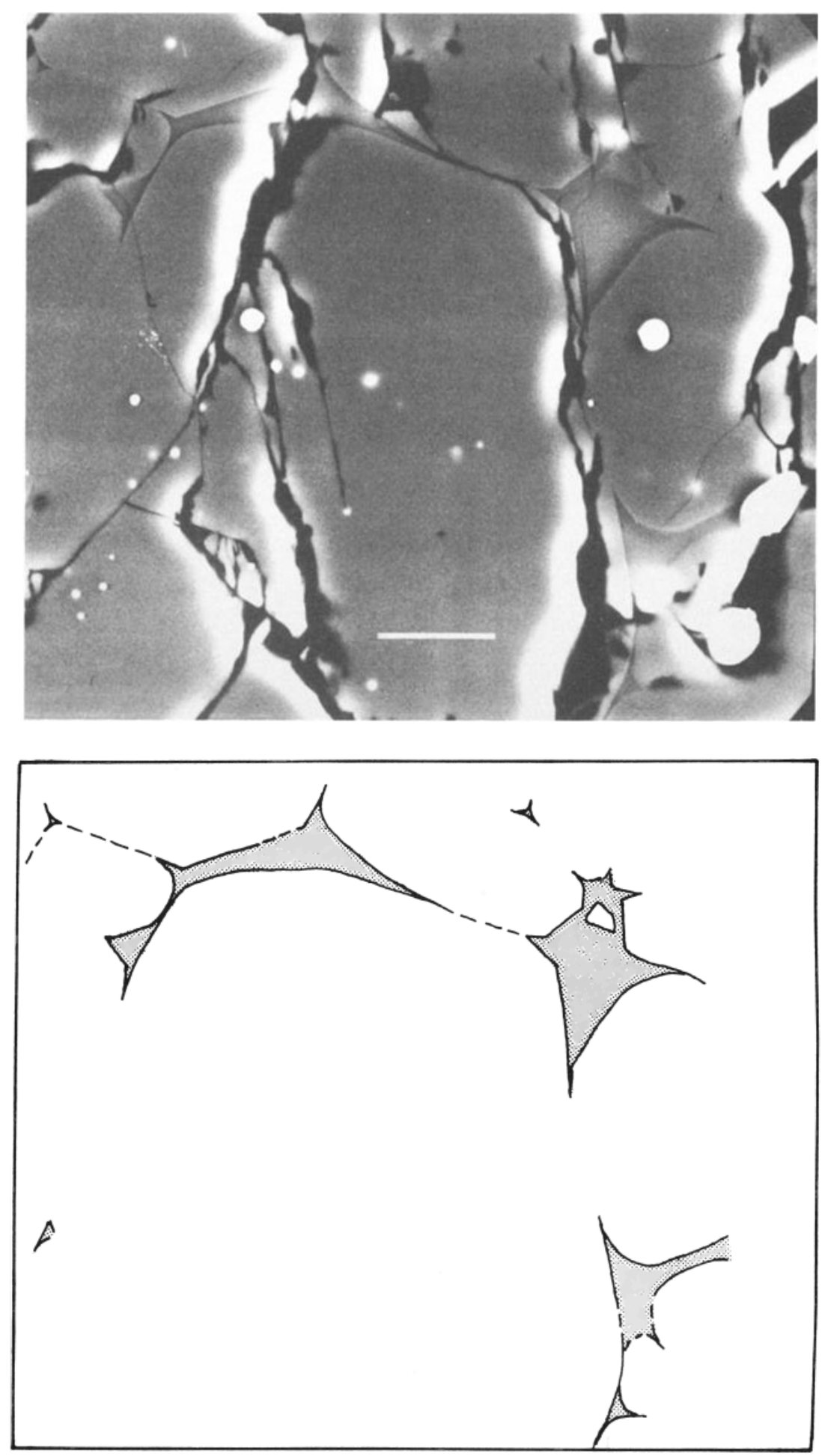

Fig. 6. BSE image from run 1 with a run duration of 530 hours. The halftone and line drawing of the melt distribution was traced directly from the photograph. Due to the low melt fraction of this run only a small number of larger melt pockets and faceted interfaces occur. Typically, the melt was confined to triple junctions, as in the top left comer. Preparation of the thin section caused the extensive fracturing. White spots are iron blebs, diffused into the sample from the sample chamber. Scale bar represents $20 \mu \mathrm{m}$.

crystallographic axes, which had flat faces perpendicular to the $b$ axis (parallel to the (010) plane) among other faceted and curved interfaces. All of these faces were observed to be wetted. It should be noted, however, that other (010) faces which are not wetted by the melt may also be present.

\section{Crystal Morphology and the Crystal-Melt INTERFACE}

Equilibrium Shape of Anisotripic Crystals

In this section, the differences in behavior between isotropic and anisotropic solids is considered in the context of crystal 


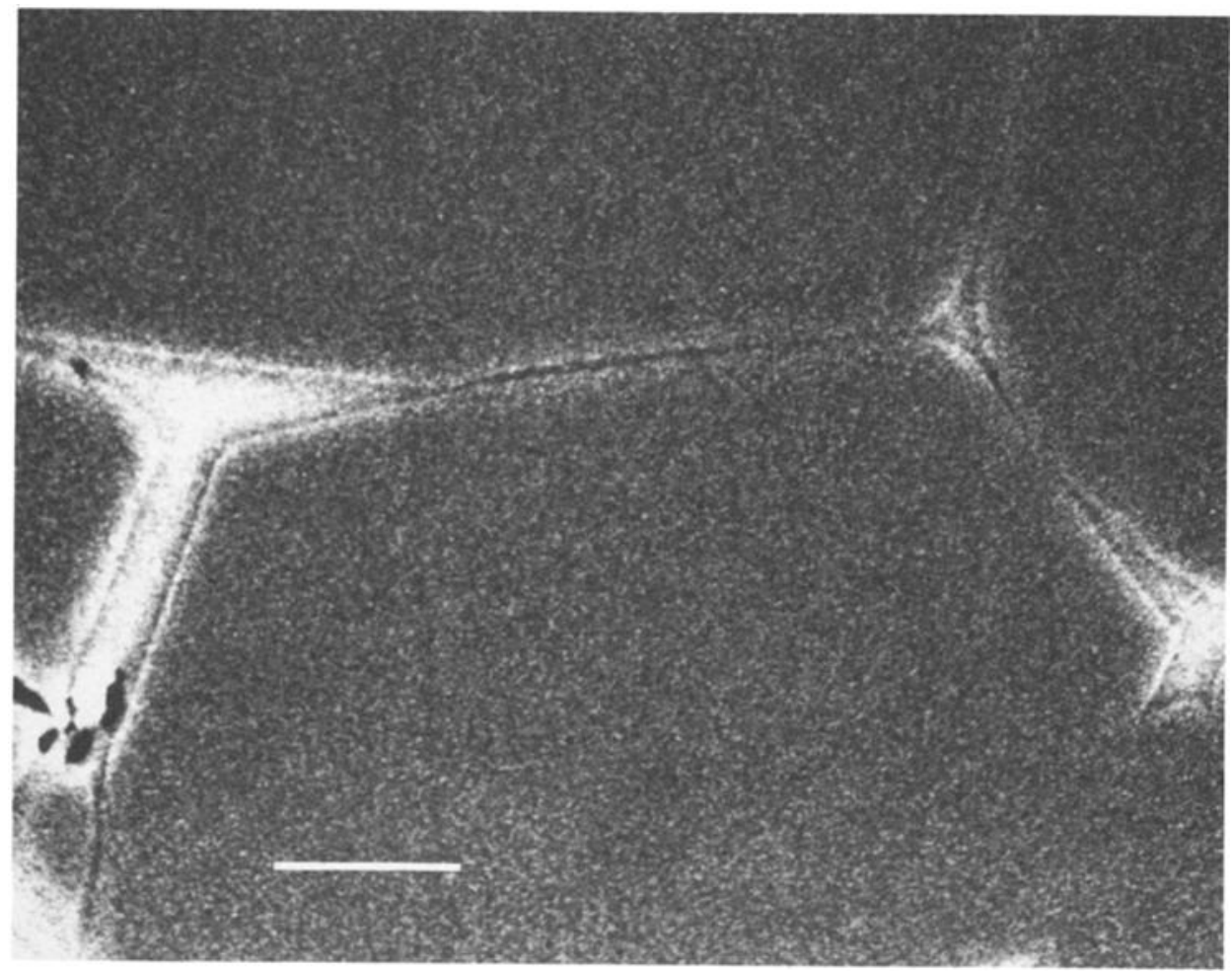

Fig. 7. A euhedral olivine grain from run 3. Several of the boundaries of this grain are wetted by the melt, the top right grain corner is part of a triple junction. The distorted symmetry of this grain is probably due to growth restrictions by adjacent grains. Scale bar represents $10 \mu \mathrm{m}$.

growth theories and their relevance to the equilibrium texture of partial melts. In the isotropic equilibrium theory of partial melts it is assumed that the surface energies of crystalline phases are isotropic. Surface tension is independent of surface

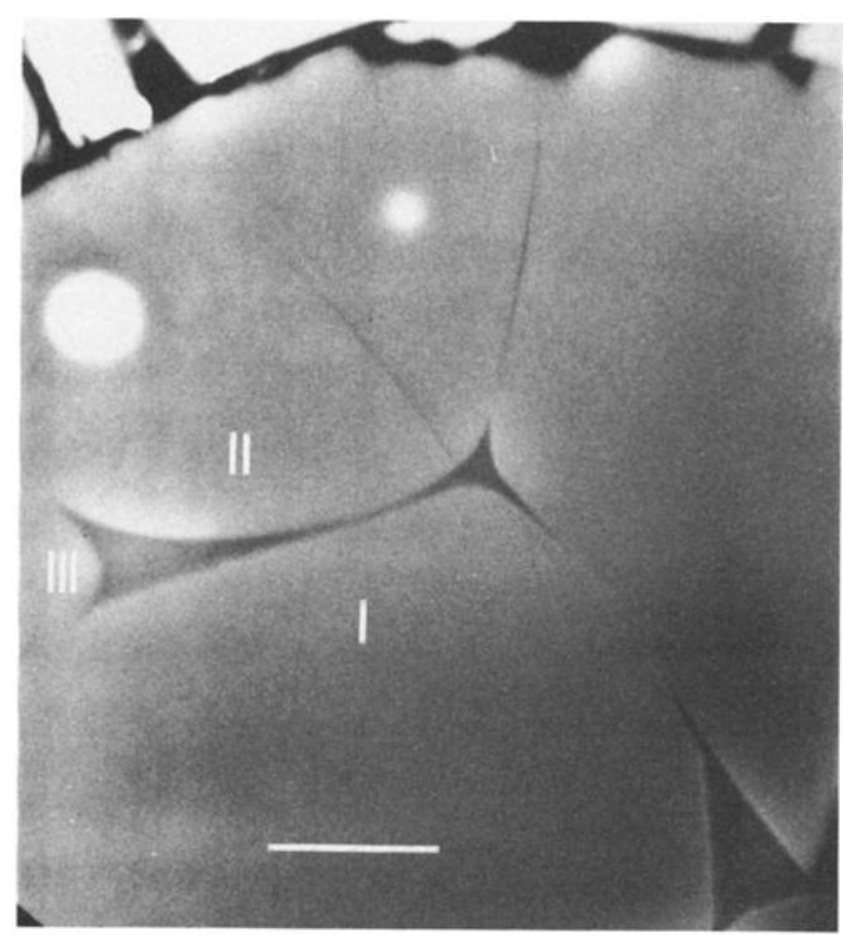

Fig. 8. BSE image of run 1: an example of partially wetted grain boundaries. Melt appears between grains I and II, but the same grain boundary of grain I with grain III is dry. Scale bar represents $10 \mu \mathrm{m}$. direction for isotropic solids. When isolated from other crystalline grains, their equilibrium shapes, derived from minimizing surface free energy, are spheres. For solids with anisotropic crystal structures, surface tensions are functions of the orientations of their respective planes, which are generally expressed by Miller indices [cf. Landau and Lifshitz, 1980]. Minimization of the surface free energy of an isolated. anisotropic grain results in an equilibrium habit which can be described by a family of intersecting planes rather than a sphere. The Wulff plot is a geometric construction of this result [Herring, 1951, 1953]. The areas of the planes which constitute the habit of a given type of crystal decrease with increasing Miller indices, and corner regions joining low-index planes often become rounded [Landau and Lifshitz, 1980]. In partially molten polycrystalline aggregates, the junctions of three grain edges accommodate melt, but the size of melt tubules residing along these junctions is restricted if adjacent crystal faces are part of the stable equilibrium habit of the neighboring grains.

Surface energies for particular faces on an isolated crystalline grain can be calculated by employing the periodic bond chain (PBC) theory developed by Hartman and Perdok [1955a, b, c]. Surface energy here is defined as the energy per unit surface area which is required to divide an infinite crystal into two halves along a specified plane [t'Hart, 1978b]. PBC theory involves the systematic search of the crystal structure for chains of strong bonds with lattice periodicity. For forsteritic olivine, where $\mathrm{SiO}_{4}$ tetrahedra are treated as crystallizing units, chains are constructed such that only $\mathrm{MgO}$ bonds are broken. If at least two connected chains are found in the same plane, the crystal face corresponding to this plane is called an $F$ (flat) face. The higher the bond energy within the plane, the lower the surface energy of the individual crystal face, and the more important the crystal face becomes for the crystal habit 
[Bennema and van der Eerden, 1987]. t'Hart [1978a b] applied PBC theory to olivine and calculated surface energies for different bond models ranging from purely ionic to purely covalent. The predicted crystal habit is elongated along the $c$ axis and slightly tabular on (010). The forms most frequently observed in natural crystals lie between those calculated using purely covalent and those calculated using mixed ionic-covalent bond models and include $\{010\},\{110\},\{120\},\{021\},\{001\}$, and $\{101\}$. Some of these forms were also reported by Schwindinger and Anderson [1989] to be present among olivine phenocrysts from the picritic scoria of the 1959 Kilauea Iki eruption. Drury and van Roermund [1989] studied fluidrecrystallized peridotite xenoliths from the Thaba Putosa kimberlite pipe in South Africa. They found that euhedral shaped tablet grain boundaries are sub parallel to crystal growth habits in olivine and orthopyroxene. Their universal stage measurements showed $[010\}$ and $\{110\}$ as the most common olivine forms, followed by $\{120\},\{021\}$, and $\{102\}$. These observations from natural crystals confirm the theoretically predicted and experimentally observed crystallographic control of flat crystalline faces.

\section{Surface Tensions}

Surface tensions between solid and liquid play an active role in determining melt distribution, but crystallographically controlled $\mathrm{F}$ faces remain flat in polycrystalline aggregates including partial melts. The wetting angle, $\theta$, as a direct expression of the balance of surface tensions, $\sigma$, between solid grains and melt is not unique in polycrystalline aggregates with anisotropic surface tensions. This surface tension or force balance can be expressed as [cf. Bulau et al., 1979]

$$
\frac{\sigma_{\mathrm{S} 1 ; \mathrm{L}}}{\sin \theta_{1}}=\frac{\sigma_{\mathrm{S} 2 ; \mathrm{L}}}{\sin \theta_{2}}=\frac{\sigma_{\mathrm{S} 1 ; \mathrm{S} 2}}{\sin \theta_{3}}
$$

where $\sigma_{\mathrm{S} ; \mathrm{L}}$ depends on the crystalline surfaces involved and in general $\sigma_{\mathrm{S} 1 ; \mathrm{L}}$ is not equal to $\sigma_{\mathrm{S} 2 ; \mathrm{L}}$, and therefore $\theta_{3}$, the angle enclosing the liquid, varies. For isotropic crystals (1) simplifies to

$$
\cos \frac{\theta}{2}=\frac{\sigma_{\mathrm{S} ; \mathrm{S}}}{2 \sigma_{\mathrm{S} ; \mathrm{L}}}
$$

This equation has been presented in the literature with surface tensions replaced by surface energies. This formulation is correct only in the isotropic case and is therefore invalid in partial melts containing anisotropic solids. It is, nonetheless, remarkable that this equation indicates that the entire range of wetting geometries from "pinch-off," where isolated melt pockets commence at $\theta=60^{\circ}$, to complete grain boundary wetting at $\theta=0^{\circ}$ can be accomplished by changing the ratio of the surface tensions by only $15 \%$.

\section{The Stability of Flat Faces}

Both faceted and curved interfaces occur, often on the same crystal. The presence of curved interfaces away from threegrain-edge intersections must be consistent with the theoretical considerations discussed above. Isinglike statistical mechanical models have been used to successfully describe the stability of $F$ faces as a function of temperature for various crystalline materials [Bennema and van der Eerden, 1987]. Originally developed to explain the transition from ferromagnetic to paramagnetic behavior in metals at their specific Curie temperatures, Ising models predict the breakdown of long-range order at these temperatures. For crystalline $F$ faces similar order-disorder transitions exist. Suppose that a step or edge is introduced on an otherwise flat crystal plane whose bond energy has been calculated with the PBC theory. If the free energy of that edge is greater than zero, the edge will be unstable and the surface will revert to being flat (atomically smooth). With increasing temperature, the edge free energy decreases until, at a certain temperature, it vanishes completely. This temperature is referred to as the roughening temperature, $T_{r}$, since it determines the onset of atomic roughness of the surface corresponding to the breakdown of its long-range order. Each crystalline $F$ face has a different roughening temperature which is dependent on the bond energies within its plane. Generally, the higher the planar bond energy, the higher the value of $T_{r}$ and the lower the surface energy of the $F$ face in question [Bennema and van der Eerden, 1987]. Two points should be noted: (1) at temperatures which are elevated, but below the melting point of a crystalline phase, both smooth and curved interfaces can occur simultaneously on the same grain, and (2) faces which are above $T_{r}$ can more easily assume whatever curvature is needed to accommodate melt. The appearance of $F$ faces in interfacecontrolled (i.e., near equilibrium) growth or dissolution of olivine and pyroxene and the recognition of two types of interface growth mechanisms, rough (continuous growth) versus smooth (growth by a layer-spreading mechanism) bave also been documented elsewhere [Donaldson, 1985; Tsukamoto et al., 1983].

\section{DISCUSSION}

\section{Dependence of Crystal-Melt Morphology on Melt Fraction}

Evidence from the recently conducted experiments reported in this paper, and from the earlier studies cited, are broadly consistent with a melt morphology which changes its character as a function of melt fraction as follows. At very low melt fractions the crystal-melt morphology is dominated by triplejunction tubules (melt at three-grain-edge intersections) and dry grain boundaries, as has been amply documented in the literature. However, even at melt fractions below 1 vol \%, deep penetration of melt between grain boundaries and flat or faceted interfaces are observed experimentally (see Figures 4, 6 and 8). One effect of flat interfaces on permeability is as follows. The cross sectional area of the midpoint of a melt triple junction, where "neck-off" occurs, will be increased significantly if one flat interface occurs in place of a curved interface, as shown in Figure 9. The axis of the triple junction will be constrained to be parallel to the $F$ face by the inherent stability of the latter over curved interfaces with which the $F$ face is in contact to make the melt tubule. The presence of the flat interfaces will, then, increase permeability by diminishing the amount of "neckoff" occurring along associated triple-junction melt tubules, other factors being equal.

In experimental run products with melt fractions of $2.5 \mathrm{vol} \%$ and $3.5 \mathrm{vol} \%$, most of the melt occurs in melt pockets and, to a lesser extent, in films which wet some of the grain boundaries (Figure 2). The melt pockets are possibly due to variable grain sizes and irregular grain geometries as compared to the idealized model of the space-filling geometry of truncated 


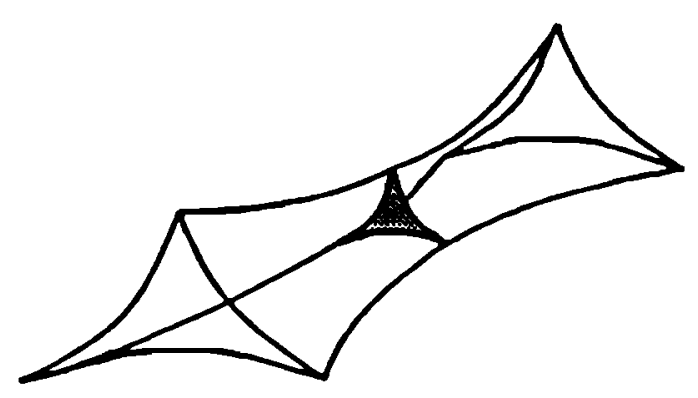

(a)

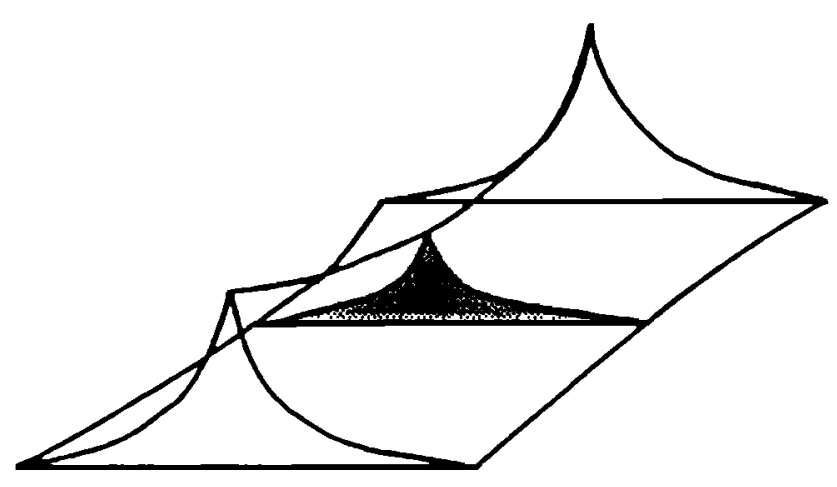

(b)

Fig. 9. (a) Depiction of the prismatic melt volume along an intergranular edge intersection when all three interfaces between melt and crystalline grains have constant mean curvature and $(b)$ a similar melt section with two curved interfaces and one flat or faceted interface. Note that the stippled, minimum cross-sectional area of the channel in Figure $9 b$ is greatly enhanced over that in Figure $9 a$ as a result of the flat face.

octahedra [cf. Figure 3 in von Bargen and Waff, 1986]. The melt, including that contained in pockets, remains completely interconnected throughout the samples by the network of triplejunction tubules. Increases in permeability with increasing porosity may be constrained at these melt fractions, since tubule cross sections are not observed to grow significantly with further increase in melt fraction. At the same time, it appears that the stability of certain crystalline $F$ faces will provide for an increasing number of adjacent grains separated by melt films with increasing melt fraction.

\section{Grain Boundary Wetting}

Comments are in order concerning the wetting of $F$ faces which we have indicated are minimum surface energy features of the crystal habit. The crystallographically controlled $F$ faces are minimum surface energy features of the crystal habit when the crystal is isolated from other crystal grains and is only in contact with its melt. In a polycrystalline aggregate the grain boundary energy is directly related to the number density and magnitude of unsatisfied bonds existing across the interface. An F face controlled by one crystal grain will force the grain boundary between it and an adjacent crystal to remain flat, but it does not also constrain the energy of the grain boundary separating the two crystals to be small, even though its surface energy, when in isolation from other grains, may be small. The misfit of bonds across the boundary can be quite large when one of the adjoining crystals constrains the boundary to be one of its
$F$ faces. Therefore the presence of melt between two grain boundaries can lower the total grain boundary energy for some relative grain orientations. An indication that grain boundary orientation determines the wetting behavior is given in Figure 8, where melt separates the grains labeled I and II, but the same grain boundary of grain I with grain III is dry.

Intergranular, highly siliceous glass phases with thicknesses of the order of $1 \mathrm{~nm}$ have been reported for a variety of ceramic materials [cf. Clarke, 1987]. These films are produced under partially molten conditions. Clarke [1987] showed that an attractive Van der Waals interaction between the grains on either side of the boundary, and a repulsive term associated with the structure of the liquid, can lead to an equilibrium thickness of the film. Estimated values of film thickness are close to values measured in a number of ceramic materials. Their predicted and measured thicknesses are orders of magnitude smaller than the micron thicknesses of intergranular films reported by us in this study. Because of the limits of SEM resolution we cannot preclude the existence of very thin films (of nm thicknesses) along grain boundaries which appear to be unwetted in our experimental run products. However, the TEM results of Vaughan et al. [1982], on a sample of similar composition and equilibrated under similar conditions in our laboratory, provide evidence against the universal wetting of grain boundaries in these silicate partial melts. Additional evidence opposing universal grain boundary wetting and retention of melt/glass nm thicknesses films comes from natural rocks. Waff and Holdren [1980] found, in a surface electron spectroscopic study of Hawaiian dunites, evidence against the widespread retention of melt/glass nm thicknesses films along grain boundaries in these mantle-derived rocks.

\section{Preferred Crystallographic Orientation}

Both theory and the frequency of occurrence of the $(010)$ faces in natural olivine-bearing rocks and experimentally produced ultramafic partial melts emphasize their existence and stability within rocks of the upper mantle. Although needed experimental data are incomplete, the potential consequences of these $\mathrm{F}$ faces to partial melt physical properties, especially when lattice preferred orientation (LPO) occurs, are sufficiently important that we believe they should be pointed out. Examples, which will be elaborated below, are that the prevalence of some crystalline $F$ faces may help explain the retention of melt beneath oceanic crust away from the ridges, and the focusing of melt toward mid-ocean ridges .

Evidence for LPO within oceanic and continental mantle is provided by the fabrics of ultramafic rocks of upper mantle origin [cf. Christensen, 1984] and from seismology [cf. Tanimoto and Anderson, 1984; Silver and Chan, 1988]. Away from the immediate vicinity of mid-ocean spreading ridges, observed seismic anisotropy requires alignment of the olivine a axes within the upper mantle sub parallel to the spreading direction. Petrofabric analysis supports this observation and provides evidence that, in many cases, the olivine $b$ axes are aligned approximately perpendicular to the Mohorovicic' discontinuity [Christensen, 1984] (see Figure 10).

L.PO can, depending on the degree to which it is attained, have two qualitatively opposing effects on melt permeability in mantle partial melts. If the olivine (010) faces, and possibly others, remain largely wetted and the olivine grains attain approximate alignment with each other, then permeability anisotropy should occur, since wetted faces play a major role in 


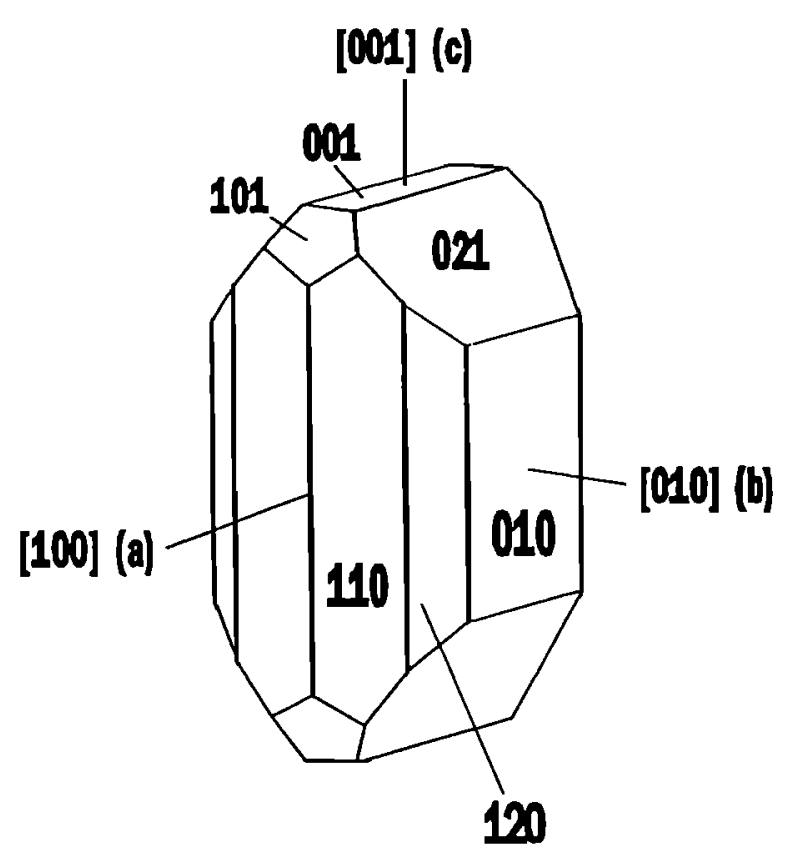

Fig. 10. Forsterite $\left(\mathrm{Mg}_{2} \mathrm{SiO}_{4}\right)$ with its most prominent forms [after Deer, et al., 1978]. Seismic velocities in the various crystallographic directions are as follows: for a axes, $9.29 \mathrm{~km} / \mathrm{s}$; for b axes, $7.72 \mathrm{~km} / \mathrm{s}$; and for $c$ axes, $8.43 \mathrm{~km} / \mathrm{s}$. The olivine composition in our experiments is $\mathrm{Fo}_{90}$.

permeability, at least at melt fractions exceeding about one percent. The importance of the $(010)$ faces of olivine is further emphasized by Wulf's law which indicates that they dominante olivine surface area among all forms [cf. Thompson, 1987]. If they remain wetted in the upper mantle, as we typically observe in laboratory experiments, then enhanced horizontal and diminished vertical permeability should occur in any remaining regions of partial melt where this fabric is developed. We expect this behavior to dominate at the moderately high degrees of LPO typically derived from ophiolites and also required to explain observed upper mantle seismic anisotropy. On the other hand, crystallographic alignment can be strong enough to expel melt from the $F$ faces. It is well known that strong grain boundary energy reduction occurs with very low mismatch angles of tilt or twist between grains in metal systems [cf. Van der Merve, 1950; Read and Shockley, 1952]. Qualitatively similar behavior is expected in silicates. However, the very high degrees of intergranular alignment required to expel melt from otherwise wetted grain boundaries which involve both tilt and twist misorientations occur infrequently in upper mantle sections of ophiolites [Christensen, 1984]. In addition, the degree of olivine LPO required to fit observed upper mantle seismic anisotropy appears to be too weak to produce a large fraction of very low angle grain boundaries. Therefore, we consider it likely that LPO attained in upper mantle rocks is sufficient to produce permeability anisotropy through aligned, wetted $F$ faces, but not generally great enough to significantly reduce the wetting of $F$ faces of olivine grains. If this speculation is correct, then the required vertical alignment of olivine $b$ axes and horizontal alignment of $(010)$ faces should result in horizontally enhanced and vertically diminished permeability. This anisotropy could inhibit remaining melt, that did not segregate to become part of the MORB, from rising under gravitational buoyancy and solidifying at the base of the lithosphere, thereby extending the life of partially molten zones in sub oceanic asthenosphere which is moving away from spreading ridges.

The dominance of the $(010)$ faces of olivine in natural rocks and in experimentally produced partial melts also provides a potentially important mechanism for facilitating magma collection from large volumes of upwelling asthenosphere beneath ocean spreading ridges. Ribe $[1989 a b]$ modeled the development of deformation-induced lattice preferred orientation (LPO) of the dominant olivine slip system (010)[100] beneath mid-ocean ridges (MORs). For the corner flow solution of Batchelor [1967] the flow was found to be equivalent to simple shear at each point. Locally, the shear plane is oriented along the radial direction toward the ridge axis, independent of the distance from the ridge crest. According to Ribe's model, the slip system of olivine becomes increasingly aligned in this direction until a maximum is reached when the material "freezes" onto the crust. This occurs for both Newtonian and power law rheologies and is consistent with Karato's [1987] findings of kinematic control (dislocation glide) of LPO at the temperature and stress conditions beneath a MOR. Ribe and $Y u$ [1991], in a theoretical model for plastic deformation, concluded that in an olivine polycrystalline aggregate, deformed under progressive plane strain, the majority of the [100] crystal axes are near the semimajor axis and the [010] axes are near the semiminor axis of the strain ellipsoid, confirming the development of LPO as indicated above. Consequently, the prevalence of $(010)$ faces in partial melts that we observe experimentally, together with their radial alignment toward ridge axes in response to maximum shear directions, should result in directional permeability which may help focus melt toward the ridges.

An important question is whether or not crystalline grain surfaces can reorganize themselves to maintain minimum surface energies on a time scale which is faster than that of flow beneath ridges. As a relevant example, olivine bulk diffusion rates of $3 \times 10^{-11} \mathrm{~cm}^{2} / \mathrm{s}$ would, even at a fast spreading ridge (i.e., $9.0 \mathrm{~cm} / \mathrm{yr}$ halfrate), allow complete chemical equilibration of grains with radii of $1.5 \mathrm{~cm}$ over a duration of only 5500 years. This corresponds to a flow distance of about $500 \mathrm{~m}$. With the increased bulk diffusivities which would result from the presence of melt, reorganization of crystal surfaces to minimize surface energy will be significantly faster than the time scales of the flow beneath ridges.

\section{Effects of F Faces on Partial Melt Bulk Physical Properties}

Several important bulk physical properties of partial melts, in addition to permeability, will also be significantly effected by the presence of $F$ faces. Bulk rock viscosity will be reduced by the presence of melt films wetting a significant fraction of the grain boundaries by increasing the bulk rock diffusivity and possibly enhanced grain boundary sliding. O'Connell and Budiansky [1977] and Schmeling [1985] have shown that melt inclusions with very small aspect ratios, such as melt films between grain boundaries, have the most profound effect on seismic velocities and attenuation. Schmeling [1986] finds qualitatively similar effects on electrical conductivity. Both of these bulk physical properties of mantle partial melts are expected to be anisotropic for anisotropic melt distributions. If melt tubules occurring along triple junctions within partial melts in the upper mantle are limited in effective cross sectional area, as we observe experimentally, then the effects of $F$ faces on all the aforementioned bulk physical properties will be strongly accentuated. 


\section{SUMMARY}

The main conclusions of this paper are as follows: Experimental and theoretical evidence demonstrates that crystallographically controlled, flat crystalline interfaces exist as stable, pervasive features in steady state or near-equilibrium partial melts representative of the Earth's upper mantle, and (2) their presence has to be accounted for in models of melt extraction and other bulk physical properties. Accordingly, the wetting angle is not the only parameter governing the distribution of melt in a crystalline matrix for most melt fractions. The equilibrium habits of constituent mineral phases, with their associated crystallographically controlled $F$ faces, will also exert a strong influence on the steady state or equilibrium morphology of ultramafic partial melts. A dependence of the style of melt geometry on melt fraction is observed in the high-P, high- $T$ experiments reported in this paper, which indicates that flat crystal faces become increasingly important at higher melt fractions.

Although it is clear that the equilibrium crystal habits of constituent minerals will exert a strong influence on partial melt textures, more experimental data are needed for quantitative evaluation with regard to melt fraction and other parameters. It can, nonetheless, be stated qualitatively that the crystallographically controlled flat interfaces can produce anisotropic permeability in regions of the upper mantle where strong lattice-preferred orientation occurs. This mechanism may help explain the focusing of melt toward mid-ocean ridges and the possible trapping of some melt in the oceanic asthenosphere flowing away from ridges over extended periods of time.

Acknowledgments. This project was supported primarily by the National Science Foundation under grant EAR-8905069. Additional support was provided by GeoPacific Research and Exploration. Thanks are due to J. Chambers, and $\mathrm{H}$. Jung, for assistance with various parts of the project. We are also grateful to $\mathrm{D}$. Johnston and anonymous reviewers for critical reviews of the manuscript.

\section{REFERENCES}

Batchelor, G. K., An Introduction to Fluid Dynamics, Cambridge University Press, New York, 1967.

Bennema, P., and J. P. van der Eerden, Crystal graphs, connected nets, roughening transition and the morphology of crystals, in Mophology of Crystals, part A, edited by I. Sunagawa, Pp. 1-77, Terra Scientific Publishing Co., 1987.

Bulau, J. R., H. S. Waff, and J. A. Tyburczy, Mechanical and thermodynamic constraints on fluid distribution in partial melts, J. Geophys. Res., 84, 6102-6108, 1979.

Christensen, N. I.. The magnitude, symmetry and origin of upper mantle anisotropy based on fabric analyses of ultramafic tectonites, Geophys. J. R. Astron. Soc., 76, 89-111, 1984.

Clague, D. A., and G. B. Dalrymple, Age and petrology of post-shield and rejuvenated-stage lava from Kaui, Hawaii, Contrib. Mineral. Petrol., 99, 202-218, 1988.

Clarke, D. R., On the equilibrium thickness of intergranular glass phases in ceramic materials, J. Am. Ceram. Soc., 70, 15-22, 1987.

Cooper, R. F., and D. L. Kohlstedt, Interfacial energies in the olivinebasalt system, Adv. Earth Planet. Sci., 12, 217-228, 1982.

Deer, W. A., R. A. Howie and J. Zussman, An Introduction to the Rockforming minerals, p. 1, Halsted, New York, 1974.

Donaldson, C. H., A comment on crystal shapes resulting from dissolution in magmas, Mineral. Mag., 49, 129-132, 1985.

Drury, M. R., and H. L. M. van Roermund, Fluid assisted recrystallization in upper mantle peridotite xenoliths from kimberlites, J. Petrol., 30 , 133-152, 1989.
Elthon, D., Pressure of origin of primary mid-ocean ridge basalts, in Magmatism in the Ocean Basins, edited by A. D. Saunders and M. J. Norry, Geol. Soc. Spec. Publ., 42, 125-136, Blackwell Scientific Pub., Oxford, 1989.

Fujii, N., K. Osamura, and E. Takahashi, Effect of water saturation on the distribution of partial melt in the olivine-pyroxene system. J. Geophys. Res., 91, 9253-9259, 1986.

Green, D. H., Experimental testing of 'equilibrium' partial melting of peridotite under water-saturated and water-undersaturated conditions, Can. Mineral., 14, 255-268, 1976.

Green, D. H., R. F. Cooper, and S. Thang, Attenuation spectra of olivinebasalt partial melts: Transformation of Newtonian creep response, Geophys. Res. Lett., 17, 2097-2100, 1990.

Hartman, P., and W. G. Perdok, On the relation between structure and morphology, I, Acta Crystallogr., 8, 49-52, 1955a.

Hartman, P., and W. G. Perdok, On the relation between structure and morphology II, Acta Crystallogr., 8, 521-524, $1955 b$.

Hartman, P., and W. G. Perdok, On the relation between structure and morphology III, Acta Crystallogr., 8, 525-529, 1955c.

Herring, $C$., Some theorems on the free energies of crystal surfaces, Phys. Rev., 82, 87-94, 1951.

Herring, C., The use of classical macroscopic concepts in surface-energy problems, in Structure and Properties of Solid Surfaces, edited by R. Gomer and C. S. Smith, pp 5-81, University of Chicago Press, Chicago, Ill., 1953.

Jackson, E. D., The character of the lower crust and upper mantle beneath the Hawaiian Islands, Proc. Int. Geol. Congr., 23 (1), 135-150, 1968.

Jurewicz, A. J. G., and E. B. Watson, Cations in olivine, 2, Diffusion in olivine xenochrysts, with applications to petrology and mineral physics, Contrib. Mineral. Petrol., 99, 186-201, 1988.

Jurewicz, S. R., and E. B. Watson, The distribution of partial melt in a granitic system: The application of liquid phase sintering theory, Geochim. et Cosmochim. Acta, 49, 1109-1121, 1985.

Karato, S. I., Seismic anisotropy due to lattice preferred orientation of minerals: kinematic or dynamic?, in High Pressure Research in Mineral Physics, Geophys. Monogr. Ser., vol. 39, edited by M. H. Manghnani and Y. Syono, Pp 455-471, AGU, Washington, D. C., 1987.

Landau, L. D., and E. M. Lifshitz, Statistical Physics, part 1, Pergamon, New York, 1980

Maaløe, S., Magma accumulation in the ascending mantle, J. Geol. Soc. London, 138, 223-236, 1981.

MacDonald, G. A., and T. Katsura, Chemical composition of Hawaiian lavas, J. Petrol., 5, 82-133, 1964.

Nicolas, A., and A. Prinzhofer, Cumulative or residual origin for the transition zone in ophiolites: Structural evidence, J. Petrol., 24, 188206, 1983.

O'Connell, R. J., and B. Budiansky, Viscoelastic properties of fluid saturated cracked solids, J. Geophys. Res., 82, 5719-5735, 1977.

Read, W. T., and W. Shockley, Dislocation models of grain boundaries, in Imperfections in Nearly Perfect Crystals, edited by W. Shocklely, J. H. Holloman, R. Maurer and F. Seitz, pp 352-376, John Wiley \& Sons, New York, 1952.

Ribe, N. M., Continuum theory for lattice preferred orientation, Geophys. J., 97, 199-207, 1989a.

Ribe, N. M., Seismic anisotropy and mantle flow, J. Geophys. Res., 94, 4213-4223, $1989 b$.

Ribe, N. M., and Y. Yu, A theory for plastic deformation and textural evolution of olivine polycrystals, J. Geophys. Res., 96, 8325-8335, 1991.

Riley, G. N., and D. L. Kohlstedt, Kinetics of melt migration in upper mantle-type rocks, Earth Planet. Sci. Lett., 105, 500-521, 1991.

Schmeling, H., Numerical models on the influence of partial melt on elastic, anelastic and electrical properties of rocks, I, Elasticity and anelasticity, Phys. Earth Planet. Inter., 41, 34-57, 1985.

Schmeling, H., Numerical models on the influence of partial melt on elastic, anelastic and electrical properties of rocks, II, Electrical conductivity, Phys. Earth Planet. Inter., 43, 123-136, 1986.

Schwindinger, K. R., and A. T. Anderson, Synneusis of Kilauea Iki olivines, Contrib. Mineral. Petrol., 103, 187-198, 1989. 
Silver, P. G., and W. W. Chan, Implications for continental structure and evolution from seismic anisotropy, Nature, 335, 34-39, 1988.

Tanimoto, T., and D. L. Anderson, Mapping convection in the mantle, Geophys. Res. Lett., 11, 287-290, 1984.

' Hart, J., The structural morphology of olivine, I, A qualitative derivation, Can. Mineral., 16, 175-186, 1978 .

t' Hart, J., The structural morphology of olivine, II, A quantitative derivation, Can. Mineral., 16, 547-560, 1978 b.

Thompson, J.B., A simple thermodynamic model for grain interfaces: some insights on nucleation, rock textures, and metamorphic differentiation, in Chemical Transport in Metasomatic Processes, edited by H. C. Helgeson, pp 169-188, D. Reidel Publishing Company, 1987.

Toramaru, A., and N. Fujii, Connectivity of melt phase in a partially molten peridotite, J. Geophys. Res., 91, 9239-9252, 1986.

Tsukamoto, K., T. Abe, and I. Sunagawa, In situ observation of crystals growing in high temperature melts or solutions, J. Cryst. Growth, 63, 215-218, 1983.

Vaughan, P. J., D. L. Kohlstedt, and H. S. Waff, Distribution of the glass phase in hot-pressed, olivine-basalt aggregates: An electron microscopy study, Contrib. Mineral. Petrol., 81, 253-261, 1982.

Van der Merve, J. H., On the stresses and energies associated with intercrystalline boundaries, Proc. Phys. Soc. (London), A63, 616-637, 1950.

von Bargen, N., and H. S. Waff, Permeabilities, interfacial areas and curvature of partially molten systems: Results of numerical computations of equilibrium microstructures, J. Geophys. Res., 91. 9261-9276, 1986. von Bargen, N., and H. S. Waff, Wetting of enstatite by basaltic melt at $1350^{\circ} \mathrm{C}$ and 1.0-2.5 GPa pressure, J. Geophys. Res., 93, 1153-1158. 1988.

Waff, H. S., and J. R. Bulau, Equilibrium fluid distribution in an ultramafic partial melt under hydrostatic stress conditions, $J$. Geophys. Res., 84, 6109-6114, 1979.

Waff, H. S., and J. R. Bulau, Experimental studies of near-equilibrium textures in partially molten silicates at high pressure, in High Pressure Research in Geophysics, Adv. Earth and Planet. Sci., 12, 1982.

Waff, H. S., and G. R. Holdren, The nature of grain boundaries in dunite and therzolite xenoliths: implications for magma transport in refractory upper mantle material. J. Geophys. Res., 86, 3677-3683, 1980.

Watson, E. B., Melt infiltration and magma evolution, Geology, 10, 236$240,1982$.

Watson, E. B., J. M. Brenan, and D. R. Baker, Distribution of fluids in the continental mantle, in Continental Mantle, edited by M. A. Menzies, Clarendon, Oxford, pp.111-125, 1990.

U. H. Faul and H. S. Waff, Department of Geological Sciences, University of Oregon, Eugene, OR 97403.

(Received March 21, 1991;

revised November 18, 1991;

accepted January 2, 1992.) 